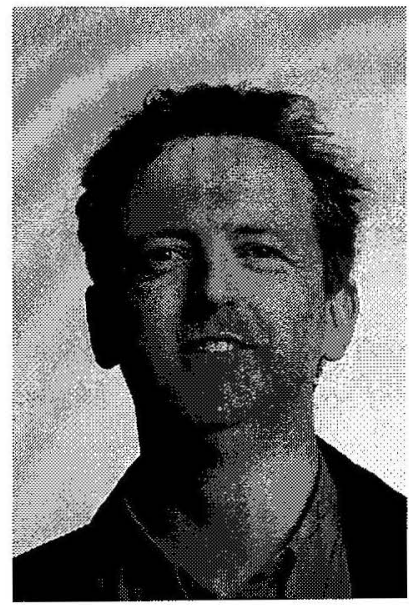

\title{
NARRATIVES OF ILLNESS AND INJURY IN THE WORKPLACE
}

\author{
Kevin Dew, Vera Keefe-Ormsby \\ and Keitha Small
}

Department of Public Health and Te Rōpu Rangahau Hauora a Eru Pōmare, Wellington School of Medicine and Health Sciences

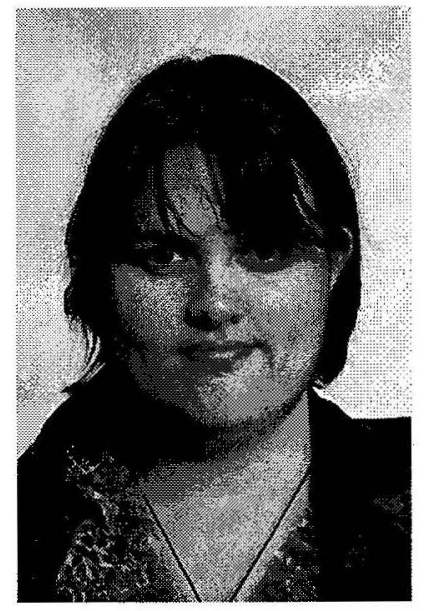

\begin{abstract}
This paper will discusses research examining workers' responses to injury and illness in the workplace, in particular what factors would encourage or discourage workers from acknowledging signs and symptoms of illness and injury. The objective of this research was to place these responses within the context of efforts to reduce injury, the organisation of the workplace and broader social factors such as workers' perceptions of the labour market and accident compensation. The paper is based on interviews and focus groups of workers from two workplace settings. Workers' perceptions of the working environment, and their narratives of illness and injury, will be discussed, with a focus on the concept of presenteeism and also entitlement to compensation.
\end{abstract}

\section{Introduction}

Recently there has been intense debate about the health and safety culture in the New Zealand workplace. This debate has been fostered by a concern about an alarming increase in workplace fatalities investigated by the Occupational Health and Safety Service (OSH) and also proposed legislative changes such as the Health and Safety in Employment Amendment Bill.

There has, however, been little New Zealand research carried out on the ways in which workers respond to the legislative environment, to their work site rules and to other social pressures influencing workplace health and safety. Overseas studies of professional and office workers suggest that there are links between 'working through illness', or 'presenteeism' (as opposed to absenteeism) and increased morbidity (Grinyer and Singleton 2000; McKevitt 1997). These studies suggest that different workplace arrangements have an impact on the overall degree of morbidity, for example worker autonomy and control over the work process has been negatively associated with coronary heart disease (Karasek and Theorell 1990). Other studies suggest that employers and employees focus on different aspects of risk in the workplace, with workers accepting the normality of risk in the work site (Dorman 1996; Dwyer 1991; Holmes and Gifford 1997; Viscusi 1983). Taken together, these studies indicate that social pressures and formal rules in the workplace may influence workers in ways that may have long-term detrimental consequences for their health (Dwyer 1991; Nichols 1997). A dominant institution in the New Zealand context in relation to workplace injury and disease is the no-fault accident compensation scheme. Due to fiscal constraints and concerns about welfare dependency the New Zealand government introduced the Work Capacity Assessment for those in receipt of ACC in 1997 (Duncan 1999). There have also been other major changes such as the privatisation and recent re-nationalisation of accident compensation. In addition assessment criteria has been used by ACC assessors that was developed on the assumption that compensation aggravates morbidity (Dew 2002; Gorman and Dryson 1998). There has been no research exploring how these changes, or how the policy environment, influence workers' decisions about claiming sickness or injury.

The research discussed here aims to bring together these issues to gain insight into the ways in which workers' perceptions of the policy environment and formal and informal workplace rules impact upon their risk-taking behaviours and responses to illness and injury. This has both national and international significance. Nationally, understanding how workers define their injuries and risks may provide insights to assist in the development of better injury prevention interventions and health promotion activities. Internationally, this research is of significance due to the interest in our unique no-fault insurance scheme and its operation. 


\section{Research Design}

The research was carried out in two phases. In the first phase interviews were undertaken with employers/managers and worker representatives. The specific aims were:

To obtain the views of employers and union representatives of the importance or otherwise of early recognition of illness and injury in the workplace.

To ascertain the views of employers and union representatives of the ways in which early recognition of injury and illness can be encouraged in the workplace.

To obtain the views of employers and union representatives of the policy environment, which may hinder or help dealing with the issues of illness and injury, suffered by workers.

Through a process of random sampling from OHS lists of workplaces 14 employers were recruited. Thirty workplaces declined participation in the research. Union representatives were recruited from the staff of four of the employers. One employer recruited two union members. For the employers that did not have union members on their staff, union members were recruited from similar workplaces

In the second phase of the research focus groups and interviews were conducted with workers at a number of workplaces to explore workers' responses to illness and injury in the workplace. Focus groups and interviews were arranged with workers in five settings - a private hospital, a public hospital, a retailer, a meatworks and a small manufacturing company. This paper will draw on material collected in the first phase of the research and on the focus groups carried out at the small private hospital and the small manufacturing company. Discussion will concentrate on the issues of presenteeism and the denial of entitlement to compensation.

\section{Phase One Findings}

In interviews with employers and worker representatives there were many sites that claimed to have good health and safety policy. Clerical sites commonly used ergonomic therapists or occupational therapists. A particular concern here was over OOS. There were also some examples of scepticism - "I have no sympathy for it" and "I painted the garage at the weekend and I didn't get OOS." Non-clerical sites commonly used external consultants for hazard identification. In larger organisations health and safety committees were established and used. Union representatives tended to be less aware of hazards. This was put down to employers having a legal obligation to deal with them and the unions having to focus on wages and contract negotiations There was little focus on psychological or emotional hazards e.g. overwork, stress etc.
Respondents recounted numerous reasons why presenteeism might be fostered. These included:

feelings of responsibility to co-workers

feelings of indispensability/dedication to the job

Worry over mounting workloads

needing the money

labour market concerns

climbing the corporate ladder

personal pride, not wanting to show weakness

Feelings of inadequacy in their job

laziness and not getting around to it

embarrassment at others knowing a worker's personal condition

"Stupidity" of employees

A cultural aspect: "from people being brought up with a very very much more relaxed attitude to perhaps their own health, or injury."

There was also a feeling that management pressure played an important role:

Staff levels are down to the bare minimum; managers do put pressure on people to turn up when they shouldn't.

The labour market and work environment could encourage presenteeism:

You've got these regulations which are quite strong ones I think, but you've also got this competitive working environment where exposing vulnerabilities, illnesses, things like that are working against that.

Many respondents noted a number of concerns about working through illness such as:

spread an illness

could make it worse

lead to loss of production

lead to resentment at having to work when ill

present a bad image of an uncaring work place

lead to negative comments from customers

However, practically speaking most respondents seem to work through minor illnesses. A common personal response to a hypothetical pain was: 
My attitude to myself is probably not the best to quote. After telling other people how to do it, I don't do it myself... It's not that I'm indispensable or anything, but...

Respondents cited a range of organisational factors that could act as a counter to presenteeism and foster early reporting of any injury or illness. These included environments that were:

"supportive and nurturing"

had a bit of "give and take"

open, honest and relaxed.

placed a high value on health

Had empathetic managers

Had managers promoting awareness of injury and illness

Had an open door policy in relation to seeing managers

Had regular staff meetings

Had regular monitoring of issues

Negative aspects to early identification included

Work piling up

lost money

stigmatisation for some people (mental illness, OOS)

employees abusing it

attitude of not whinging

Injuries can stay on your record

lack of a clearly identified structure for reporting

Negative attitude of management

It can be concluded from this first phase of the research that there are many ways in which presenteeism is fostered in the workplace. The next phase of the research attempted to gain the views of workers themselves.

\section{Private Hospital Site}

At the small private hospital site an egalitarian discourse was strongly evident. "We do all sorts of jobs so there is no distinguishing between us on the ward...we all do the same thing." Respondents also felt that they were in control of their work situation: "You organise your own workload...you consider what needs doing first". They also articulated a sense of choice about their work arrangements: "A majority of staff are part time...And that's mostly out of choice". Respondents talked of the strong support they received from their colleagues: "it has a kind of a family relationship where staff now cope well". However, there was also a theme of "coping" expressed, particular in relation to the common experience of back pain where "You learn to live with it" (B2S).

A 'family' discourse was very prominent and strongly expressed. This was fostered by management where it was felt that 'they care about us'. There was an overriding 'autonomy' and 'choice' discourse.

The "family" narrative was linked to a strong emphasis on teamwork, informal support and caring for colleagues: The workers described themselves as a "close bunch". Given the "caring family' narrative there is a concern to avoid being a malingerer: "I don't think people like to appear as if they are always off sick". This same respondent also argued that the main problem was that "people put pressure on themselves" to come to work when they were ill. The social influences on presenteeism were not seen as important. Respondents would come to work because of a loyalty to their colleagues: "I knew it was going to be busy so I thought I would come". And

I can't ring in at ten o'clock and say 'I can't, I feel dreadful tonight'. You just drag yourself along and work. And I've done that on the odd occasion because you're letting down your colleague who you work with...

For some conditions there were mechanisms in place to inhibit presenteeism. An infection control officer could send workers home if there was a concern that they would spread disease. Fellow workers might also pressure colleagues to go home for the same reason. There was a suggestion here that there needed to be some kind of institutional means to keep people from coming to work inappropriately, even in an environment where there was no perception of pressure from management to work when sick.

In sum, there was no management pressure, there were strong institutionalised processes to resist some forms of presenteeism, and a family narrative that provided a powerful motivation for presenteeism

In terms of the wider institutional environment the perception and experiences of ACC had a major impact on workers responses to injury. For a number of workers they felt that they no longer had entitlement to compensation for injury.

Note the following narrative from ' $\mathrm{B} 2 \mathrm{~L}$ ' and how this plays out in relation to a discourse of choice and entitlement. Early in the focus group B2L states:

I think that there's a high level of stress amongst the staff even here, who work full time compared to those who work part time. You have more life away from work than people who work full time. So therefore I think that you are less physically tired and you enjoy coming to work... 
most of us who work part time are obviously not having to work out of necessity to work full time, so therefore you have a different balance in your life with family and outside activities.

Then later in the interview:

\section{I: How did you find dealing with ACC?}

BL2 In the long term awkward and difficult...I was working full time then and I dropped down to four days a week and they paid for the extra day and the injury did not improve much and I was recommended by my practitioner to work three days a week. ACC would pick up one day. But after a couple of years they pressured me to change my job by saying 'this is not the right job for you and you should do something else...we would train you'... and at the end of the day I'm working for three days a week as a nurse and I can cope with that and I don't want to train as anything else...it didn't take in reality the likelihood of getting into any of these wonderful jobs in other places anyway. So I said 'this is silly I'm going to carry on what I'm doing' and they said 'we won't pay you anymore' and that's the end of that.

It is clear from this that the 'choice' to work part time is no choice at all, it becomes a necessity due to a previous injury. The respondent now 'copes'. In addition the respondent has lost her entitlement to compensation. This narrative also shows a rejection of expertise. The experts want to retrain her, but this is rejected as being unreal. The price of rejection is to take a drop in remuneration.

Two levels of 'choice' can be noted here. The workplace offers the environment that allows the respondent to 'cope'. On the other hand, in terms of the back injury and the relationship to ACC this is not choice at all - this is a restriction.

The same respondent also explained how these events had affected her views about future entitlement:

ACC were very good to me to start off with when my injury was more acute you know. As is the policy with ACC they are into rehabilitation and if they can't rehabilitate you they tell you to get another job, and I mean I've got no criticism of that policy just that it doesn't always work that way. And they are fairly blanket in their approach to it from that point of view there are many cases that come up, where pain is not so much the issue its whether you can do a different sort of job.

Later this respondent explained that her experience meant that she would no longer claim for $\mathrm{ACC}$ :

I still get pain - it was a hip injury which happened at work. And I suspect...that if I was to claim again, it still gives me pain from time to time, there would be the likelihood ACC would say you declined to go through our rehabilitation process before and you said that you wanted to carry on nursing, and you've stirred up this old injury - too bad, we told you so.

Another respondent who had an accident was also wary of being involved with ACC again: "I hope I never have to [go back to ACC]...Some times [ACC] were good and sometimes they were awful" and so "I was keen to get off".

But even without a previous history of dealing with ACC others suggested they would not take a claim for compensation:

R2: would probably be happy to go, but I don't know that I would, if I got sprained, perhaps either acute back injury at my stage in my career I would probably flag it actually.

I: Why would you do that when you might have entitlement to $\mathrm{ACC}$ ?

R2 That's a very good question.

After some further discussion an answer was offered:

R2: I probably wouldn't, as a causal employee, but then again if it was an ankle fracture or something, I would, but probably not for a back injury or whatever,

I: So can you tell me why not as a casual employee, what is different about that?

R2: Because I don't have a sick entitlement anyway, it's something I probably wouldn't do.

I: I mean you have ACC entitlement like everybody else.

R2: It would be hard to prove if it's not related to an original injury.

So there are a number of rationales for rejecting entitlement, including previous bad experiences with ACC, being a casual worker and concern about establishing proof. The issue of proof was picked up by a permanent worker:

It's hard to say because if it's an acute injury, I mean if you slip down a bank and break your ankle...I wouldn't hesitate because you could say this injury occurred at such a such a day at such a such a time and this is how the injury occurred. But when you are talking about more chronic back pain, I personally think that you would have more difficulty in persuading $\mathrm{ACC}$ that the injury that you had that may be related to your original injury nine years ago I guess, is a new injury. So it depends a bit on what the injury is whether you would consider that.

And another worker felt similar concerns:

I think of my colleague who was in a car accident. I think she's probably going to have problems further down the track cause she's got pins and plates and things. And I 
mean working in a job coming back to nursing and working in a job, and if she does an injury how do you... yeah I think they are quite harsh and sometimes unsympathetic to people in those sorts of circumstances.

Workers have internalised a view that exacerbation of old injuries, even work-related ones, were not compensatable.

I: so if you, just a hypothetical situation, if you put your back out moving a patient and you were bed ridden for ...more than a week...would you go to ACC do you think or not.

R2: Yeah, I don't think I would initially, because I mean I haven't had an injury and ...that would be a first claim for me...

The respondent went on to say:

But what concerns me is if you had, as the others have said, if you re-injure I suppose, how sympathetic are they towards you when you actually go back if it's a result of the original injury.

The respondent is suggesting that she will cope with some injuries so as not to have problems with $\mathrm{ACC}$ at a later time.

It can be concluded from this that there are not only a host of reasons for presenteeism, but also a host of reasons for denial of entitlement. These include bad experiences in the past, the rehabilitation process, fear of trouble in the future, the internalisation of ACC's position on 'old' injuries, and a belief that casual workers are not really entitled. It can be suggested here that the concern expressed by some about the possibility of 'compensation neurosis' needs to be weighed against these issues.

\section{Small Manufacturing Site}

The small manufacturing site provides a stark contrast with the private hospital site. Whereas management at the hospital site were seen as fostering a family atmosphere the management at the manufacturing site were seen as non-responsive and non-caring. In terms of health and safety the workers did not even have access to a sick room and "even at Christmas time they didn't wish us a happy Christmas". The following transcript provides some insight:

Spl: they have panadol for headaches

Sp2: well they used to but it went so fast they turned around and said buy your own...It's alright for me because I use that extra strength panadol because that is what I need. I don't expect the company to provide those.
Sometimes I've worked by myself in a department and you can yell and scream all you want and no one will hear you

And

one of the girl's in spinning next door to us was working on her own on the night shift...she put her hand down to get something from the machine and she went to take her hand out and the ring on her finger got jammed. She couldn't go in and she shouldn't go out and she just used brute strength to get her hand out and broke the ring...We were next door and we couldn't hear her screaming or yelling.

And

I used to have spindles flying off...So when you're on the machine you watch out and duck

Sp1: You are going as fast as you can and they tell you to go faster.

\section{Sp2: And they say you are not doing enough}

Sp3: and the extreme heat in that place

The lack of facilities promoted unsafe conditions:

Sp1: We put cardboard down cause we've got no mats

Sp2: I tripped on a cardboard box the other week. I got my foot on it and I went flying

Sp3: cause I had my machine running one night and I was walking down and I tripped and I was heading head first into the spinners and it was just the fact I put my hands out that stopped me, but I could have killed myself. They should have rubber work mats on the floors

Another worker stated that:

I was so stressed and so hot that I hit the deck. Out cold. Slapped my head on the concrete... the bosses didn't even come to see if I was OK

And

Sometimes I get home in the afternoon and I can't get up my back steps. I crawl into the shower and then hit my bed. And I am out for two or three hours before I can think about cooking tea or anything.

Pressure to work when sick came from management, for example:

I'm an asthmatic and occasionally it plays up and I've found now it's better to ring up early and get the answer phone whereas if you speak to one of the bosses he's very rude. He gives you the third degree 'surely you're well enough to come back'

Workers at times felt compelled to work when they did not want to, noting little choice: 
It is hard for me to get a job at my age so you keep the on you've got

I think if you speak to $95 \%$ they will say they would get another job if there was one.

I mean I was on the dole for seven months and I tell you, having a job, you appreciate it. I was getting $\$ 186$ a week on the dole

It's the same with doing overtime. They come to you at 4.30 and say you're working tomorrow, Saturday morning. Most of us think that if we don't take it we lose the overtime.

\section{Conclusion}

This research indicates that there are very powerful forces motivating presenteeism in the current working environment in New Zealand. They range from structural issues such as the state of the labour market through to concerns about overloading work colleagues. In an environment where management appears hostile to the plight of workers presenteeism can be driven by management. But even where management is supportive presenteeism is prominent. These forces provide a strong counter to efforts to try and get workers to recognise symptoms of illness and injury at an early stage so that appropriate action can be taken to prevent deterioration in health status.

In addition the research indicates that there are many instances where workers will deny themselves the opportunity to obtain compensation for injury. This is in stark contrast to the often-articulated concern about the malingering worker and the construction of diagnostic categories such as compensation neurosis. The self-denial of compensation and presenteeism could be forms of risktaking behaviour that are detrimental to the health and safety of workers and of the public that come into contact with them.

There are many areas in which further research could be conducted to explore these issues in more depth. Developing some measure of presenteeism would enable researchers to undertake studies to gauge the prevalence of this phenomenon. More qualitative research around the denial of entitlement, including the views of ACC assessors and case managers on issues such as compensation neurosis and presenteeism, would shed light on the compensation environment. Research on strategies to discourage presenteeism, such as 'injury' control officers, could also be undertaken. Case studies of workplaces operating under various health and safety arrangements (e.g. with a company doctor, without health and safety committees etc) would also shed more light on the issue of presenteeism.

It should be noted that this paper is based on an initial analysis of the data and the interpretation of the qualitative date collected is ongoing. The qualitative data collected is rich and detailed and provides insights into the working environment that could not easily be obtained using other research strategies.

\section{Acknowledgements}

We would like to thank the Lottery Grants Board for funding this research and Ryan Monastra for collecting the data for the first phase of the research.

\section{References}

Dew, K. (2002) Accident insurance, sickness, and science: New Zealand's no fault system. International Journal of Health Services, 32,163178.

Dorman, P. (1996). Markets and Mortality. New York: Cambridge University Press.

Duncan, G. (1999) The assessment of residual capacity for work: Easier said than done. Social Policy Journal of New Zealand, 12, 35-52.

Dwyer, T. (1991) Life and Death at Work: Industrial Accidents as a Case of Socially Produced Error. New York: Plenum Press.

Gorman, D. and Dryson, E. (1998) Diagnosis of chemical poisoning: Report of a working party established by the Australasian Faculty of Occupational Medicine, Royal Australasian College of Physicians, Auckland, 9 May 1997. New Zealand Medical Journal, 111, 362-364.

Grinyer, A. and Singleton, V. (2000) Sickness absence as risk-taking behaviour: A study of organisational and cultural factors in the public sector. Health, Risk and Society, 2, 7-21.

Holmes, N. and Gifford, S. (1997) Narratives of risk in occupational health and safety: Why the 'good' boss blames his tradesman and the 'good' tradesman blames his tools. Australian and New Zealand Journal of Public Health, 21, 11-16.

Karasek R. and Theorell, T. (1990) Health Work: Stress, Productivity, and the Reconstruction of Working Life. New York: Basic Books.

McKevitt, C. et.al. (1997) Sickness absence and 'working through' illness: A comparison of two professional groups. Journal of Public Health Medicine, 19, 295-300.

Nichols, T. (1997) The Sociology of Industrial Injury. London: Mansell.

Viscusi, W. (1983) Risk by Choice: Regulating Health and Safety in the Workplace. Cambridge, Massechusetts: Harvard University Press. 